\title{
FORMAÇÃO CONTINUADA EM EDUCAÇÃO ESPECIAL E A COOPERAÇÃO
} INTERSETORIAL ${ }^{1}$

\author{
Ana Paula Cunha dos Santos Fernandes
}

Resumo

Analisar a cooperação entre os setores do governo estadual voltados para a formação continuada em educação especial é o objetivo deste artigo. Configura-se de abordagem qualitativa e os dados foram analisados com aproximação de autores da área e legislação vigente. Participaram da referida formação continuada trezentos profissionais da rede estadual entre professores, técnicos e gestores de todo o estado do Pará. Os resultados mostram pontos positivos como a interação e cooperação entre a secretaria de educação e a universidade; e negativos em relação à educação a distância, como ausência de familiaridade com a plataforma utilizada. Registra-se que houve aproximação das instituições nos diferentes níveis, refletindo na cooperação dentro das escolas.

Palavras-chave: educação; formação continuada de professores; intersetores.

\section{CONTINUED TRAINING IN SPECIAL EDUCATION AND} INTERSECTORIAL COOPERATION

\begin{abstract}
Analyze the cooperation among the state's governmental sectors focused on continued education in Special Education is the purpose of this article. It is a qualitative approach; the data were analyzed with approximation of authors of the area and current legislation. Three hundred professionals from the state's educational system have participated of the continued education including teachers, technicians and managers from all over the state of Pará. The results demonstrate positive points such as interaction and cooperation between the Department of Education and the University; and negative points regarding Distance education course such as lack of familiarity with the platform. It is recorded that there was an approach of institutions in different levels, reflecting in the cooperation within schools.
\end{abstract}

Keywords: education; continued education of teachers; intersectoriality.

\section{FORMACIÓN CONTINUADA EN EDUCACIÓN ESPECIAL Y COOPERACIÓN} INTERSETORIAL

Resumen

Analizar la cooperación entre los sectores del gobierno estadual dirigidos a la formación continuada en Educación Especial es el propósito de este artículo. Se configura como un abordaje cualitativo y los datos fueron analizados con aproximación de autores del área y legislación vigente. Han participado de la formación continuada trescientos profesionales de la red estadual entre profesores, técnicos y gestores de todo el estado de Pará. Los resultados muestran puntos positivos como la interacción y cooperación entre la Secretaría de Educación y la Universidad; y negativos en relación a la educación a distancia, como ausencia de familiaridad con la plataforma utilizada. Se registra que hubo aproximación de las instituciones en los diferentes niveles, reflejando en la cooperación dentro de las escuelas.

Palabras clave: educación; formación continua de professores; intersetores.

\footnotetext{
${ }^{1}$ Financiamento Governo do Estado do Pará.
} 
DOI: $10.12957 /$ teias. $\%$ Y.50232

\section{INTRODUÇÃO}

Este artigo surge a partir da parceria e cooperação entre a Universidade do Estado do Pará (UEPA) e a Secretaria de Educação do Estado do Pará (SEDUC) de 2017 a 2018. É resultado do diálogo entre o Grupo de Estudos e Pesquisas em Educação Especial na Amazônia (GEPEEAm) e o Programa de Pós-Graduação em Educação, ambos vinculados à UEPA, a SEDUC, representada pela Coordenadoria de Educação Especial (COEES), a Unidade de Ensino Especializado (UEES) Professor Astério de Campos e o Centro de Formação dos Profissionais da Educação Básica do Estado do Pará (CEFOR), todos da instância estadual.

A proposta articulada abrange, em um primeiro momento, formação presencial e, depois, em plataforma virtual, os trezentos professores da educação básica de educação especial e classe comum advindos de diferentes regiões do Pará.

O projeto objetivou fomentar discussões, estudos e pesquisas sobre Surdocegueira e Deficiência Múltipla Sensorial no contexto amazônico e articular a intersetorialidade proposta na política de inclusão; ainda, identificar o público surdocego e o que possui Deficiência Múltipla Sensorial; compreender as necessidades e especificidades desses públicos da educação especial no contexto escolar; contribuir para a formação de professores, dando atenção às práticas pedagógicas adotadas com esses públicos; formar agentes multiplicadores para atuação com pessoas com tais especificidades na rede estadual de ensino; também, atualizar os indicadores escolares referente aos públicos-alvo em questão.

Configura-se como pesquisa participante de cunho qualitativo, pois, como descreve Godoy (1995, p. 62), visa

[...] à compreensão ampla do fenômeno que está sendo estudado, considera que todos os dados da realidade são importantes e devem ser examinados. O ambiente e as pessoas nele inseridas devem ser olhados holisticamente: não são reduzidos a variáveis, mas observados como um todo.

Sobre a pesquisa participante com o foco na educação dá-se ênfase a Campos (1984, p. 64) “[...] trata-se, no fundo, de uma proposta pedagógica... a rever as práticas de pesquisa e a rever as práticas escolares."

De acordo com Freitas (2013, p. 237), o incentivo a grupos de estudos e pesquisa de professores, em redes de formação, pesquisa, produção e desenvolvimento da educação organicamente articulados aos sistemas de ensino, é meta a ser perseguida. Compreende-se, nesse sentido, que há contributo com a participação dos grupos de pesquisa na discussão e, principalmente, no diálogo e formação com os professores.

O estudo está organizado da seguinte maneira: inicialmente, realiza-se uma breve discussão sobre a pessoa surdocega e a pessoa com Deficiência Múltipla Sensorial, em seguida, apresenta-se o censo dessa população, a formação continuada em educação especial e a formação continuada a distância.

Destaca-se que a UEES Professor Astério de Campos atualmente integra a estrutura organizacional da SEDUC como uma das unidades da COEES, sendo referência no atendimento educacional ao aluno surdo, surdo com deficiências associadas e surdocego (LIMA, LINHARES, 2017, p. 95).

Lima e Linhares (2017, p. 95) destacam que a Unidade:

[...] foi regulamentada pelo Conselho Estadual de Educação (Resolução nº 311 de 25 de outubro de 2012), sendo assim autorizada a oferta da escolaridade, por 
meio da Educação Infantil em nível de Pré-Escola; do Ensino Fundamental $1^{\circ}$ ao $5^{\circ}$ ano; e da Educação de Jovens e Adultos - Fundamental $1^{a}$ e $2^{a}$ etapas, o direito de acessibilidade comunicacional ao aluno surdo, ao surdocego e aos que apresentam múltiplas deficiências. O Atendimento Educacional Especializado (AEE), que tem como um dos seus objetivos oferecer apoio pedagógico especializado no contraturno aos alunos surdos que têm atendimento em salas de recursos, em salas de apoio e em ensino itinerante, apesar de integrar as ações da [UEES], na oportunidade não foi regulamentado e nem autorizado pelo Conselho Estadual de Educação devido à ausência de normativas estaduais que regularizem esse atendimento. Deste modo, a [UEES] segue as diretrizes nacionais para a organização do AEE com adequações que se estabelecem por conta das especificidades da realidade da Unidade.

Os autores afirmam ainda que a UEES Professor Astério de Campos cumpre seu compromisso oferecendo o ensino voltado para as especificidades das pessoas atendidas, principalmente, as linguísticas (LIMA, LINHARES, 2017, p. 107).

\section{UMA BREVE APRESENTAÇÃO SOBRE A PESSOA COM SURDOCEGUEIRA E A PESSOA COM DEFICIÊNCIA MÚLTIPLA SENSORIAL}

Para Cader-Nascimento e Costa (2010), a Surdocegueira é o comprometimento dos sentidos receptores a distância (audição e visão). As autoras relatam, com base em McInnes (1999), que, para classificar uma pessoa como surdacega, é necessário que ela não tenha visão suficiente para compensar a perda auditiva ou vice-versa. Assim entende também Pacco e Silva (2015), referenciando autores como Agostini e Costa (2006) e Galvão e Miranda (2013), que consideram a deficiência única e a combinação da perda da audição e da visão como impossibilitadora do uso dos sentidos a distância.

Aráoz (1999) salienta que, nesta definição, a palavra-chave é combinação. A pessoa com uma perda substancial da visão e da audição experimenta uma combinação de privação de sentidos que pode causar extrema dificuldade para alcançar as metas essenciais da vida.

Aráoz e Costa (2008) apresentam estudo desenvolvido com 19 mães e um pai de surdocegos, com idade entre quatro e 39 anos, que frequentavam uma instituição de ensino especializado na grande São Paulo. O estudo, realizado por meio de entrevistas, aborda aspectos psicossociais e apresenta dados referentes ao desenvolvimento de habilidades alcançadas por este grupo, tais sejam:

Dependência: necessitam de auxílio total para todas as atividades e expressam seus gostos ou desgostos por sinais naturais, como choro, recusa, sorriso.

Colaboração: necessitam de algum auxílio, mas colaboram com as atividades. Tem comunicação expressiva para as atividades básicas e para algumas de sua preferência.

Atividades de Pessoal: realizam as atividades de higiene, alimentação e recreativas, com independência, e têm comunicação expressiva para isto.

Atividades de Vida Social: realizam as atividades de vida diária e também outras atividades na família e na escola como: cozinha, arrumação, artesanato. Tem habilidades para tarefas simples na comunidade próxima, vizinhança ou igreja e exercem comunicação expressiva adequada para estes desempenhos. 
Conceitos de Ensino Fundamental: realizam todas as atividades dos níveis anteriores e praticam desenho, leitura, escrita e dominam as 4 operações. Têm comunicação expressiva por escrita ou por sinais ou desenhos que lhes permite expressar-se sobre o passado e o futuro, necessidades e sentimentos.

Conceitos de Ensino Médio: realizam todas as atividades anteriores e estudam as disciplinas do ensino médio. São independentes para ir e vir trabalham e convivem normalmente na sociedade, usam a leitura e a escrita para comunicarem-se de um modo geral e se expressam com maior facilidade com as pessoas capazes de compreender o sistema de comunicação alternativa por eles usados (ARAÓZ, COSTA, 2008, p. 26).

As autoras Cader-Nascimento e Costa (2010) destacam que a definição utilizada no Reino Unido parece mais precisa e abrangente e vai além dos aspectos dos sentidos, fazendo ainda:

Referência às principais implicações da surdocegueira no desenvolvimento humano, ao período de surgimento, ao diagnóstico e prognóstico e incluem pessoas que funcionam como surdas-cegas (CADER-NASCIMENTO, COSTA, 2010, p. 20).

No Brasil, as autoras destacam que a prestação de serviços educacionais e atendimento aos surdocegos se deu em 1960, após a visita de Helen Keller em 1953.

Cader-Nascimento e Costa (2010) descrevem que a Associação Brasileira de Educação de Deficientes Visuais - ABEDEV reativou o programa de atendimento ao surdocego em 1977. Nesse percurso, cabe destacar que houve mudanças na nomenclatura utilizada, são elas:

[...] dupla deficiência sensorial, múltipla privação sensorial (MPS), deficiência audiovisual (DAV), deficiência auditiva e deficiência visual (DA/DV), surdezcegueira e, atualmente surdocegueira (SC) (CADER-NASCIMENTO, COSTA, 2010, p. 16).

Inicialmente, a Surdocegueira era considerada como uma subcategoria da Deficiência Múltipla como DV/DA (BRASIL, 1995); o termo surdocegueira passou a ser considerado nas Diretrizes Nacionais para a Educação Especial na Educação Básica (BRASIL, 2001).

Já a Deficiência Múltipla “[...] tem sido utilizada para caracterizar o conjunto de duas ou mais deficiências associadas, de ordem física, sensorial, mental, emocional ou de comportamento social" (BRASIL, 2006.).

Pletsch (2015, p. 14), citando Brasil (2006), destaca que

A deficiência múltipla se caracteriza por um conjunto de duas ou mais deficiências - de ordem física, sensorial, mental, entre outras - associadas (BRASIL, 2006). Ou seja, é uma condição que afeta em maior ou menor intensidade o funcionamento individual e social dos sujeitos com essa deficiência.

A autora ainda enfatiza que:

Historicamente, os alunos com deficiência múltipla não tiveram acesso a processos de ensino e aprendizagem, especialmente por serem vistos como incapazes. Muitas dessas pessoas ficavam confinadas em casa sem acesso a qualquer intervenção educacional. Felizmente, essa realidade tem mudado nos últimos anos graças aos avanços científicos e à ampliação dos direitos educacionais das pessoas com deficiências em geral (PLETSCH, 2015, p. 22). 
Cargnin e Vieira (2012) destacam como conclusão de sua pesquisa, com base na percepção dos pais e professores, que os alunos têm dificuldades para acompanhar os conteúdos em sala de aula, alertando para o fato de que o olhar inclusivo deve ser propositor de mudanças e inquietações no sentido de considerar as pessoas, suas histórias, concepções, percepções, etc.

As autoras registram que:

\begin{abstract}
Neste sentido, a formação profissional passa a ser uma questão central para a implantação da escola inclusiva. Acima de tudo, a predisposição para perceber o aluno como ser cognoscente e como peça importante no desenvolvimento do aluno, de forma a co-responsabilizar-se pelas mudanças que urgem serem realizadas no processo educacional, se traduz como uma questão urgente a ser enfrentada no trabalho com os professores (CARGNIN, VIEIRA, 2012, p. 125).
\end{abstract}

Masini (2011) analisou produções sobre Surdocegueira e Deficiência Múltipla e destaca um aspecto convergente apontado em quase todas as pesquisas: a falta de informação. Mães não recebiam informações após o nascimento das crianças nem sobre os estímulos adequados; para os professores também falta informação sobre o que poderia facilitar a aprendizagem, por exemplo. A autora destaca que são resultados sistematizados e analisados que trazem o que, na prática, os educadores (famílias e profissionais) de pessoas surdocegas e com Deficiência Múltipla têm experienciado em seu cotidiano.

\title{
O CENSO DA POPULAÇÃO COM SURDOCEGUEIRA E COM DEFICIÊNCIA MÚLTIPLA
}

A pessoa surdocega ou a com Deficiência Múltipla possui particularidades que, às vezes, são desconhecidas das demais pessoas que atuam na escola, o que, por vezes, pode mascarar a presença desta em seu interior, lugar no qual acaba sendo registrada como se fosse duas pessoas, uma com cegueira e outra com surdez. Tal situação é semelhante ao que ocorre no caso da Deficiência Múltipla, em que se registra apenas a deficiência "que mais se destaca" ou a "mais visível". Esta foi uma das questões que mais chamou a atenção, ressaltando-se que isso gera impacto direto no censo escolar.

Com base nas informações dos índices de matrícula de 2016, que indica a porcentagem de matrículas de alunos com deficiência, transtornos globais do desenvolvimento e altas habilidades ou superdotação em classes comuns, há um total de 32.928 matriculados, correspondente a 98,3\% segundo o MEC/INEP/DEED/Censo Escolar.

As informações do quadro a seguir, com índices de 2010 do IBGE, quanto às dificuldades permanentes relacionadas à visão e audição da população entre 4 e 17 anos que está na escola, reforçam a necessidade de estudos e pesquisas sobre a Surdocegueira e a Deficiência Múltipla Sensorial que fundamentem ações de educação inclusiva em interface com outras políticas públicas, considerando a intersetorialidade e o compartilhamento de ações de inclusão e acessibilidade, pautadas no princípio de gestão democrática e participativa para a garantia dos direitos fundamentais da pessoa com deficiência.

No Estado do Pará, no ano de 2017, a princípio, 10 pessoas com Surdocegueira estavam matriculadas na rede pública de ensino, com a seguinte distribuição: 
DOI: $10.12957 /$ teias. $\%$ Y.50232

Quadro 1- Matrícula na Rede Estadual de Ensino

\begin{tabular}{|c|c|c|c|}
\hline Ure & Município & Deficiência & Quantidade de matrícula \\
\hline 01A -Bragança & Bragança & Surdocegueira & 1 \\
\hline 08A-Castanhal & Castanhal & Surdocegueira & 1 \\
\hline 14A-Capanema & Peixe boi & Surdocegueira & 1 \\
\hline 19A-Belém & Belém & Surdocegueira & 1 \\
\hline 19A-Belém & Belém & Surdocegueira & 5 \\
\hline 19A-Belém & Belém & Surdocegueira & 10 \\
\hline
\end{tabular}

Fonte: SEDUC-SIGEP: Relatório de Alunos com Deficiência por escola. Ano: 2017

O referido quantitativo de alunos (no Quadro 1) reforça a necessidade de identificá-los com maior precisão no universo populacional especificado no Censo de 2010 e nos índices de matrícula de 2016, destacando-os do conjunto de pessoas com deficiência, transtornos globais do desenvolvimento e altas habilidades ou superdotação em classes comuns, considerando a universalização com a garantia de sistemas educacionais inclusivos, orientados para a ampliação do investimento nas condições de acesso e permanência, com práticas pedagógicas e organização dos serviços direcionadas para esse público, relacionados às seguintes estratégias do Plano Estadual de Educação (PARÁ, 2015, p. 46):

4.3) implantar, no âmbito de suas competências, ao longo deste PEE, salas de recursos multifuncionais e fomentar a formação continuada de professores e professoras para o atendimento educacional especializado nas escolas urbanas, do campo, indígenas e de comunidades quilombolas;

4.7) garantir, em regime de colaboração, a oferta de educação bilíngue, em Língua Brasileira de Sinais - LIBRAS como primeira língua e na modalidade escrita da Língua Portuguesa como segunda língua, aos (às) alunos (as) surdos e com deficiência auditiva de 0 (zero) a 17 (dezessete) anos, em escolas e classes bilíngues e em escolas inclusivas, nos termos do art. 22 do Decreto no 5.626, de 22 de dezembro de 2005, e dos arts. 24 e 30 da Convenção sobre os Direitos das Pessoas com Deficiência, bem como a adoção do Sistema Braille de leitura para cegos e surdocegos.

Relacionado ao estudo e à pesquisa, a estratégia 4.14 do Plano Estadual de Educação destaca o seguinte:

[...] auxiliar o Ministério da Educação, nos órgãos de pesquisa, demografia e estatística competentes, a obtenção de informação detalhada sobre o perfil das pessoas com deficiência, transtorno global do desenvolvimento e altas habilidades/superdotação de 0 (zero) a 17 (dezessete) anos (PARÁ, 2015, p. 48). 
Com essa perspectiva filosófica, política e educacional em relação à criação de ações concretas para a garantia de direitos da pessoa com deficiência, é de suma importância o investimento em ações como a que privilegia a formação continuada de professores, em específico, com a temática de práticas e saberes inerentes à Surdocegueira e à Deficiência Múltipla Sensorial, objetivando, com o tema, fomentar discussões e pesquisas no contexto amazônico.

Essa proposta de formação é primordial para a garantia dos direitos da pessoa com deficiência, especificamente o da escolarização que, de acordo com o art. $2^{\circ}$, da Lei de Diretrizes e Bases da Educação Nacional (LDB), n 9.394 (BRASIL, 1996), “[...] tem por finalidade o pleno desenvolvimento do educando, seu preparo para o exercício da cidadania e sua qualificação para o trabalho".

\title{
FORMAÇÃO CONTINUADA EM EDUCAÇÃO ESPECIAL
}

O Ministério da Educação norteou a proposta do Plano Nacional de Educação (2011-2020) considerando, dentre as premissas, a "[...] excelência na formação e na valorização dos profissionais da educação", ainda, em continuidade, a formação continuada prioritariamente como pósgraduação, como descrito na meta 16: “[...] Formar 50\% dos Professores da Educação Básica em nível de pós-graduação stricto e lato sensu, em cursos de especialização, mestrado ou doutorado, e garantir a todos formação continuada em sua área de atuação”.

A justificativa dada no referido documento é a de que

\begin{abstract}
Além da formação em nível superior na área de atuação, é desejável que os professores aprofundem seus conhecimentos por meio de cursos de pósgraduação. Ao passar por esses cursos, sejam eles stricto sensu ou lato sensu, os professores são expostos a metodologias científicas, aprofundam seus conhecimentos, ampliam seu olhar com relação à sala de aula e, consequentemente, tem maior propensão a estimular o raciocínio científico em seus alunos (BRASIL, 2010, p. 93).
\end{abstract}

Há também um parágrafo em que se destaca a importância da formação continuada para a profissão docente:

É importante destacar a importância da formação continuada para a profissão docente, também contemplada na meta 16. A formação continuada, por meio de cursos de atualização/treinamentos oferecidos em horário de serviço, permite que o professor se atualize e esteja permanentemente fazendo a ligação entre teoria e prática, fundamental para o bom desempenho em sala de aula (BRASIL, 2010, p. 94).

Barreto (2015, p. 694) descreve que "[...] a formação continuada de docentes em serviço é uma função assumida predominantemente pelos sistemas de educação" com enorme variedade de cursos que se disseminaram pelo país com recursos das próprias redes, e, mais recentemente, pelo Ministério da Educação (MEC) por meio do sistema Universidade Aberta do Brasil (UAB).

A formação continuada é uma necessidade do profissional, que precisa manter-se informado, adquirindo novos conhecimentos, que atendam as suas demandas profissionais, motivado e renovado em suas atividades cotidianas.

Para Chimentão (2009, p. 3): 
a formação continuada passa a ser um dos pré-requisitos básicos para a transformação do professor, pois é através do estudo, da pesquisa, da reflexão, do constante contato com novas concepções, proporcionado pelos programas de formação continuada, que é possível a mudança. Fica mais difícil de o professor mudar seu modo de pensar o fazer pedagógico se ele não tiver a oportunidade de vivenciar novas experiências, novas pesquisas, novas formas de ver e pensar a escola.

Corrobora-se com Diniz-Pereira (2013, p. 221) que não se deve esquecer que existe uma tendência recorrente em nosso país e em outros de culpabilizar os professores por todas as mazelas da educação escolar, sem que sejam levadas em conta questões estruturais e de recursos disponíveis aos professores e à educação.

De acordo com a Política Nacional de Educação Especial na Perspectiva da Educação Inclusiva (BRASIL, 2008), a educação especial é uma modalidade transversal aos níveis e modalidades de ensino e:

O Plano Nacional de Educação - PNE, Lei n. 10.172/2001, destaca que "o grande avanço que a década da educação deveria produzir seria a construção de uma escola inclusiva que garanta o atendimento à diversidade humana". Ao estabelecer objetivos e metas para que os sistemas de ensino favoreçam o atendimento aos estudantes com deficiência, transtornos globais do desenvolvimento e altas habilidades/superdotação, aponta um déficit referente à oferta de matrículas para estudantes com deficiência nas classes comuns do ensino regular, à formação docente, à acessibilidade física e ao atendimento educacional especializado (BRASIL, 2008, p. 4).

Em geral, a formação continuada de professores é segmentada por área de conhecimento e, para os que atuam na educação especial, há dificuldade em dialogar com alguns professores por estes desconhecerem a condição e informações mínimas sobre os alunos com deficiência. Prevêse que a educação especial, assim como deve perpassar todos os níveis e modalidades de ensino previstos na legislação vigente, como a LDB (BRASIL, 1996) e a Lei Brasileira de Inclusão da Pessoa com Deficiência (BRASIL, 2005), deve constar na formação continuada das distintas áreas de saber e conhecimento.

A formação continuada proposta em parceria e cooperação foi voltada para o professor que trabalha ou tem interesse nas pessoas com Surdocegueira e com Deficiência Múltipla Sensorial, tanto os de sala de aula comum quanto os da Sala de Recurso Multifuncional. A temática da formação continuada tem pouca visibilidade, mas possui grandes desafios a superar; sobre isso, Lima (2014, p. 1) destaca que:

A educação de pessoas com surdocegueira no Brasil ainda é um campo pouco explorado, dada à literatura escassa, assim como o conhecimento das práticas educacionais direcionadas a essas pessoas. Desta afirmação emerge o interesse que nos leva a estudar a surdocegueira e corresponde, ainda, ao entendimento da complexidade que envolve esse processo.

São poucos os estudiosos da Surdocegueira e da Deficiência Múltipla Sensorial, assim como é escassa a formação específica para os profissionais. Compreende-se como Nóvoa (1997, p. 26) que "[...] a troca de experiências e a partilha de saberes consolidam espaços de formação mútua, nos quais cada professor é chamado a desempenhar, simultaneamente, o papel de formador e de 
formando". Sendo assim, buscou-se, por meio da participação dos professores da UEES Professor Astério de Campo, de duas professoras da UEPA (uma mestre e outra doutora), da equipe de coordenação e formação do CEFOR, do setor de tecnologia, junto a duas professoras (uma doutora e uma doutoranda) especialistas da região sudeste, a hibridação necessária para potencializar a formação continuada proposta.

A UEPA dispõe em seu Plano de Desenvolvimento Institucional (2017) ações que permitem inferir a continuidade e o fortalecimento da proposição apresentada, dentre as quais se destaca a sua missão em "[...] produzir, difundir conhecimentos e formar profissionais éticos, com responsabilidade social, para o desenvolvimento sustentável da Amazônia no contexto brasileiro" (UEPA, 2017, p. 14). Além disto, o Plano destaca como meta 1 para a pós-graduação "[...] ampliar em $100 \%$ o apoio ao desenvolvimento de projetos de pesquisa e iniciação científica", coadunandose com a Responsabilidade Social da UEPA, que enfatiza ser imprescindível:

Incentivar projetos de investigação local e regional, em diversas áreas. Incentivar projetos de ensino, pesquisa e extensão referentes aos dilemas sociais mais imediatos. Incentivo à promoção de eventos voltados também para as necessidades e dilemas sociais. Desenvolver na Universidade um programa de atividades envolvendo direitos humanos e cidadania. Dentro desse programa, propiciar: (1) o conhecimento e a reflexão a respeito da fome, miséria, desemprego, violência, exclusão, relações entre o mundo do trabalho e os problemas sociais; (2) a compreensão da situação específica das localidades onde existem Campi e regiões de abrangência, no contexto nacional, no que se refere a esses problemas; (3) reflexões sobre as relações entre o mundo do trabalho e os problemas sociais; (4) a formulação de estratégias de ação social para intervir nesse processo (UEPA, 2017, p. 51).

Compreende-se que um professor melhor qualificado e consciente de sua atuação e relevância garantirá ao aluno com deficiência, aqui Surdocego e com Deficiência Múltipla, o disposto na Lei Brasileira de Inclusão da Pessoa com Deficiência:

Art. 27. A educação constitui direito da pessoa com deficiência, assegurados sistema educacional inclusivo em todos os níveis e aprendizado ao longo de toda a vida, de forma a alcançar o máximo desenvolvimento possível de seus talentos e habilidades físicas, sensoriais, intelectuais e sociais, segundo suas características, interesses e necessidades de aprendizagem (BRASIL, 2015, p. 14).

Ainda sobre este saber, Freire enfatiza que "[...] a educação tem caráter permanente. Não há seres educados e não educados" (FREIRE, 1979, p. 28), complementando que este é um saber que se encontra em relação dialética com a sua negação, a ignorância, além de ser uma atividade em que se ensina e se aprende:

Toda prática educativa demanda a existência de sujeitos, um que, ensinando, aprende, outro que, aprendendo, ensina, daí o seu cunho gnosiológico; a existência de objetos, conteúdo a serem ensinados e aprendidos; envolve o uso de métodos, de técnicas, de materiais; implica, em função do seu caráter diretivo, objetivo, sonhos, utopias, ideais (FREIRE, 1996, p. 70).

Consonante às ideias de Freire, Freitas (2006) corrobora que a formação do professor, de modo geral, deve incluir programas e conteúdo que o ajudem no desenvolvimento de competências para atuar em situações singulares. Para a autora, a formação é entendida como um processo 
contínuo e permanente de desenvolvimento, o que pede do professor disponibilidade para a aprendizagem.

Assim, foram idealizados dois momentos: o primeiro com três dias dedicados às discussões teóricas associadas às inúmeras práticas pedagógicas desenvolvidas por professores de educação física, língua portuguesa, matemática, dentre outras áreas; e o segundo momento, em plataforma $\mathrm{EaD}$, com $60 \mathrm{~h}$ dedicadas ao aprofundamento teórico, bem como ao compartilhamento de atividades e à oferta de espaços de discussão; além disso, foram viabilizadas inúmeras produções da área para livre consulta.

No momento presencial, foram definidas mesas de discussão e palestras que permitissem a difusão de conhecimento, do mais elementar ao mais complexo, com posturas e práticas educacionais, foram elas: 1) Surdocegueira e Deficiência Múltipla Sensorial: perspectivas contemporâneas; 2) Desafios no cotidiano da família e da escola; 3) Políticas Públicas e indicadores educacionais de alunos surdocegos e com Deficiência Múltipla na escola; 4) Formação de profissionais e os desafios cotidianos dos alunos surdocegos e com Deficiência Múltipla Sensorial; 5) Formação de Professores, Prática e Recursos Pedagógicos para pessoas surdocegas e com Deficiência Múltipla Sensorial; 6) Surdocegueira e Deficiência Múltipla Sensorial: aspectos pedagógicos no Contexto Curricular; 7) Orientação e Mobilidade; 8) Parâmetros de Acessibilidade para Pessoa surdocega e com Deficiência Múltipla Sensorial: interfaces comunicacionais; 9) Currículo Pedagógico e Funcional para pessoas Surdocegas e com Deficiência Múltipla Sensorial.

Houve a participação de representante da Ordem dos Advogados do Brasil - seção Pará, familiares e pessoas com Surdocegueira e Deficiência Múltipla Sensorial e uma representante da Associação Educacional para Múltipla Deficiência (AHIMSA). Houve, também, exposição de atividades e material produzidos pelos professores da UEES Professor Astério de Campos.

O CEFOR viabilizou, aos professores de educação especial e professores de sala comum, técnicos e gestores de todo o Pará diárias e passagens para que pudessem estar na capital Belém para participar dessa inédita formação na rede estadual e para a região norte.

\section{FORMAÇÃO CONTINUADA A DISTÂNCIA}

Silva e Abranches (2015, p. 10) enfatizam que as atuais tecnologias de informação e comunicação possibilitaram uma nova configuração para a educação a distância, que, anteriormente, ocorria por meio de correspondência impressa, pela transmissão de aula via satélite, complementadas por materiais didáticos impressos, além de fitas de áudio, conferências por telefone, videoconferências, etc. Os autores descrevem ainda que a $\mathrm{EaD}$ atualmente faz uso de ambientes virtuais, ou seja, plataformas computacionais desenvolvidas para o oferecimento de cursos a distância, possibilitando, assim, uma alternativa de ampliação para a formação de professores.

$\mathrm{Na}$ formação proposta, foi utilizado o Google Sala de Aula, uma plataforma leve, de fácil organização e bom armazenamento. A proposta contou com trezentos profissionais participantes e foram criadas cinco turmas, com o mínimo de três tutores. Os tutores, professores e apoiadores não tiveram proventos para desempenho de atividades. Em geral, os envolvidos eram alunos do mestrado em educação e professores da educação básica que mantinham disponibilidade e interesse na discussão. Houve formação para melhor manuseio da plataforma, também feita por profissional da rede estadual.

No ano de 1996, com a promulgação da LDB, ocorre a normatização da educação a distância. Dentre os artigos nos quais a lei faz menção a EaD, destaca-se o 80 que diz: 
DOI: $10.12957 /$ teias.\%Y.50232

O Poder Público incentivará o desenvolvimento e a veiculação de programas de ensino a distância, em todos os níveis e modalidades de ensino e de educação continuada. $\int 1^{\circ}$ A educação a distância, organizada com abertura e regime especiais, será oferecida por instituições especificamente credenciadas pela União (BRASIL, 1996).

A discussão perpassa pelo curso de graduação e pós-graduação e sobre as possíveis distorções da proposta inicial de democratização ao acesso e permanência no Ensino Superior. Há estudo específico sobre EaD como a tese de Sentanin (2017).

Ao realizar avaliação da proposta de formação (presencial e EaD), pontos positivos e negativos foram elencados: a) positivos: participação e adesão de muitos professores do estado do Pará; depoimentos sobre a relevância da formação, da disponibilidade de leituras e material audiovisual; b) pontos negativos: frieza nas relações da plataforma educacional; desmotivação, que culminou na evasão de alguns - aproximadamente $91,3 \%$-, sendo que, aqueles que evadiram, antes de deixar a plataforma, realizaram o download do material disponibilizado; por fim, a falta de habilidade para navegar na internet.

Para Sentanin (2017), o fator desistência pode estar associado à falta de apoio acadêmico, falta de tempo, devido à sobrecarga de trabalho, dificuldades em lidar com as tecnologias, dentre outras. A autora cita ainda o trabalho de Abbad, Carvalho e Zerbini (2005), que realizaram uma pesquisa com a finalidade de detectar as principais causas da evasão em cursos que são oferecidos gratuitamente a distância em nível nacional por meio da internet. Os resultados apontaram que os alunos que não concluíram o curso eram aqueles que não utilizavam os recursos eletrônicos de interação, como o mural de notícias, chats e troca de mensagens eletrônicas. As autoras acreditam que esses recursos de interação auxiliam efetivamente na aprendizagem de uma formação, mas destacam que o importante é discutir também outros aspectos que podem ser causas da evasão como "[...] as implicações teóricas e metodológicas" e a "[...] necessidade de inclusão de variáveis motivacionais, cognitivas e contextuais".

A situação descrita pelas autoras também foi observada na formação proposta. Embora tenha sido idealizada levando-se em consideração o pouco tempo para estudo, com propostas de leituras mais acessíveis, interatividade também com outras mídias, alguns professores evadiram.

É possível visualizar no portal do MEC o Programa de Formação Continuada de Professores na Educação Especial - modalidade a distância:

O Ministério da Educação, por intermédio da Secretaria de Educação Especial, desenvolve em parceria com o programa Universidade Aberta do Brasil - UAB o Programa de Formação Continuada de Professores na Educação Especial que tem por objetivo formar professores dos sistemas estaduais e municipais de ensino, por meio da constituição de uma rede nacional de instituições públicas de educação superior que ofertem cursos de formação continuada de professores na modalidade a distância.

Na citação acima, identifica-se a cooperação com o próprio MEC e a sugestão para que se constitua uma rede de instituições em prol da formação de professores dos sistemas estaduais e municipais.

Assim, embora o nível de aproveitamento não tenha sido de cem por cento, a coordenação recebeu inúmeros depoimentos de professores da rede estadual sobre a satisfação de ter tido acesso ao curso proposto. 
Houve reunião pós-evento com representação de todos os envolvidos e sintetizou-se a seguinte consideração:

[...] consideramos que o evento foi de grande valia, pois nos trouxe questionamentos relevantes acerca da formação na educação especial e problematizou a dívida histórica que a política de formação tem com as temáticas referentes à educação especial/inclusiva.

A discussão sobre Surdocegueira e Deficiência Múltipla Sensorial precisa ser realizada nos ambientes de formação inicial e continuada para que se visibilize e fomente ações.

\section{CONSIDERAÇÕES FINAIS}

A discussão sobre propostas de formação continuada (presencial e a distância) não está esgotada e espera-se que esta sirva de motivação para novas proposições organicamente articuladas.

Dentre os pontos positivos da formação, realizada em esquema de parceria e cooperação, destaca-se a ação dos professores participantes como multiplicadores dela nas suas escolas. Aqueles que estiveram na atividade presencial transmitiram ao vivo para os que não puderem participar e, ainda, ao retornar aos seus municípios, compartilharam em reunião na escola e formação entre eles. Outro ponto a evidenciar foi o diálogo entre os setores do governo do Estado. Em particular, há o destaque para o Centro de Formação - CEFOR que possuía pouco tempo de exercício e se dispôs intensamente.

Dentre os pontos negativos, destaca-se a ausência de familiaridade dos professores da rede estadual com a plataforma utilizada; além disso, a ausência de computadores e internet dificultou o acesso dos professores da rede, que tentavam conciliar seus estudos com as atividades no laboratório da escola. Alguns tentaram por celular mesmo, embora reclamassem da dificuldade para enxergar e manusear.

Não há como não mencionar a dedicação dos professores que palestraram durante a atividade presencial. São professores da própria rede estadual de ensino, possuidores de vasta experiência e convivência com o público Surdocego e com Deficiência Múltipla Sensorial. Nas palestras, eles puderam compartilhar suas bases teóricas, metodologias, recursos de baixo custo e inúmeras experiências.

Considera-se que as discussões sobre o público específico da educação especial aqui apresentado necessitam de mais interessados a fim de propiciar novas experiências e o compartilhamento de saberes.

\section{REFERÊNCIAS}

ABBAD, Gardênia; CARVALHO, Renata Silveira; ZERBINI, Thaís. Evasão de curso a distância via internet: explorando variáveis explicativas. In: Encontro da $A N P A D, 29,2005$, Brasília-DF. Anais... Brasília-DF: ANPAD, 2005.

AGOSTINI, Elaine Aparecida Machado; COSTA, Maria da Piedade Resende da. Aplicação de um programa para o ensino da leitura e escrita de palavras para o aluno com Surdocegueira, Periódico do Mestrado em Educação da UCDB (Série-Estudos), Campo Grande, n. 22, p. 161-173, jul./dez. 2006.

ARÁOZ. S.M.M. Experiências de pais de múltiplos deficientes sensoriais: surdocegos: do diagnóstico à educação especial. 1999. 139 f. Dissertação (Mestrado em Psicologia da Saúde), Programa de Pós- 
graduação em Psicologia da Saúde, Universidade Metodista de São Paulo/UMESP, São Bernardo do Campo, 1999.

ARÁOZ, Susana Maria Mana.; COSTA, Maria da Piedade Resende da. Aspectos biopsicossociais na Surdocegueira. Rev. Bras. Ed. Esp., Marília, v. 14, n. 1, p. 21-34, jan./ abr. 2008.

BARRETO, Elba Siqueira de Sá. Políticas de formação docente para a Educação Básica no Brasil: embates contemporâneos. Revista Brasileira de Educação, v. 20, n. 62, jul./set. 2015. DOI: http://dx.doi.org/10.1590/S1413-24782015206207

BRASIL. Lei n. 9.394 - Estabelece as diretrizes e bases da educação nacional. Brasília, 1996.

BRASIL. Diretrizes Nacionais para a Educação Especial na Educação Básica. 2001.

BRASIL. Educação infantil: saberes e práticas da inclusão: dificuldades acentuadas de aprendizagem: deficiência múltipla. 4. ed. Brasília, 2006.

BRASIL. Política Nacional de Educação Especial na Perspectiva da Inclusão. Brasília: MEC, 2008.

BRASIL. Plano Nacional de Educação (2011-2020). Brasília, 2010. Disponível em http://fne.mec.gov.br/images/pdf/notas tecnicas_pne_2011_2020.pdf. Acesso em 21 dez. 2018. BRASIL. Lei n. 13.146. Lei Brasileira de Inclusão da pessoa com Deficiência. Brasília, 2015.

BRASIL. Índice de Matrículas 2016. Brasília: MEC/Inep/DEED/Censo Escolar/Preparação: Todos Pela Educação, 2016.

BRASIL. Ministério da Educação. Programa de formação continuada de professores na Educação Especial - modalidade à distância. Disponível em http://portal.mec.gov.br/dominio-publico/192secretarias-112877938/seesp-esducacao-especial-2091755988/14188-programa-formacao-

continuada-de-professores-na-educacao-especial-modalidade-a-distancia. Acesso em 22 nov. 2018.

CADER-NASCIMENTO, Fatima Ali Abdalah Abdel; COSTA, M. P. R. Descobrindo a Surdocegueira: educação e comunicação. São Carlos: EdUFSCAR, 2010.

CAMPOS, Maria Machado Malta. Pesquisa Participante: possibilidades para o estudo na escola. Caderno de Pesquisa, São Paulo, v. 49, n. 1, p. 63-66, 1984.

CARGNIN, Andréa; VIEIRA, Noêmia Ramos. Um novo olhar sobre aluno com múltiplas deficiências: um longo caminho a percorrer. In: CARVALHO, Edemir de; CARVALHO, Carmen Silvia Bueno de Freitas. Práticas pedagógicas: entre as teorias e metodologias, as necessidades educativas especiais. Marília: Oficina Universitária; São Paulo: Cultura Acadêmica, 2012, p. 117129.

CHIMENTAO, Lilian Kemmer. O significado da formação continuada docente. In: CONGRESSO NORTE PARANAENSE DE EDUCAÇÃO FÍSICA ESCOLAR - CONPEF, 4., 2009, Londrina. Anais. Londrina, 2009. v. 1, p. 1-6.

DINIZ-PEREIRA, Júlio Emílio. Prioridades, metas, estratégias e ações para a valorização e a formação do profissional da educação. In: PINO, Ivany Rodrigues; ZAN, Dirce Djanira Pacheco e (org). Plano Nacional de Educaşão PNE: questões desafiadoras e embates emblemáticos. Brasília, DF: Inep, 2013, p. 217-228.

FREIRE, Paulo. Educação e mudança. (Coleção Educação e Comunicação, v. 1) Rio de Janeiro: Paz e Terra, 1979.

FREIRE, Paulo. Pedagogia da Autonomia: saberes necessários à prática educativa. São Paulo: Paz e Terra, 1996. 
FREITAS, Soraia Napoleão. A Formação de Professores na Educação Inclusiva: construindo a base de todo o processo. In: RODRIGUES, David (org.). Inclusão e Educação: doze olhares sobre a educação inclusiva. São Paulo: Summus, 2006, p. 161-181.

FREITAS, Helena Costa Lopes. A construção do Sistema Nacional de Formação e Valorização dos Educadores: unitário, organicamente articulado e plural. In: PINO, Ivany Rodrigues; ZAN, Dirce Djanira Pacheco e (org). Plano Nacional de Educação PNE: questões desafiadoras e embates emblemáticos. Brasília, DF: Inep, 2013, p. 229-249.

GALVÃO, Nelma de Cássia Silva Sandes; MIRANDA, Theresinha Guimarães. Atendimento educacional especializado para alunos com Surdocegueira: um estudo de caso no espaço da escola regular. Revista Brasileira de Educação Especial, Marília, v. 19, n. 1, p. 43-60, jan./mar. 2013.

GODOY, Arilda Schmidt. Introdução à pesquisa qualitativa e suas possibilidades. Revista de Administração de Empresas, São Paulo, v. 35, n. 2, p. 57-63, 1995.

IBGE. Censo 2010. Disponível em: http://www.ibge.gov.br. Acesso em 20 dez. 2018.

LIMA, Katia do Socorro Carvalho. Mediações pedagógicas com alunos com Surdocegueira no Núcleo de Atendimento Pedagógico e Funcional (NAPF) em Belém do Pará. In: CONGRESSO BRASILEIRO DE EDUCAÇÃ E ESPECIAL, 6, 2014, São Carlos. Anais... São Carlos: UFSCar, 2014. Disponível em https://proceedings.science/cbee6/trabalhos/mediacoes-pedagogicas-comalunos-com-surdocegueira-no-nucleo-de-atendimento-pedagogico-e-funcional- $\% 28 \mathrm{napf} \% 29$-embelem-do-pa\#download-paper. Acesso em 21 dez. 2018.

LIMA, Katia do Socorro Carvalho; LINHARES, Felipe Lisboa. História e Memória das Unidades Especializadas: o caso da UEES Professor Astério de Campos. In: FERNANDES, Ana Paula Cunha dos Santos. Educação Especial: cidadania, memória, história. Belém: EDUEPA, 2017, p. 80-111.

MASINI, Elcie Fortes Salzano. Pesquisas sobre Surdocegueira e deficiências sensoriais múltiplas. Construção Psicopedagógica, São Paulo-SP, v. 19, n. 18, p. 64-72, 2011.

MCINNES, John. Deaf blindness: a unique disability. In: MCINNES, John (org.). A guide to planning and support for individuals who are deaf blind. Canada: University of Toronto Press Incorporated, 1999.

NÓVOA, Antonio (org.). Os professores e a sua formação. Lisboa: Publicações Dom Quixote, 1997.

PACCO, Aline Ferreira Rodrigues; SILVA, Erika. Rímoli Mota da. A Surdocegueira no contexto escolar. Educação, Batatais, v. 5, n. 2, p. 141-166, 2015. Disponível em https://claretiano.edu.br/revista/77/revista-educacao. Acesso em 13 out 2018.

PARÁ. Plano Estadual de Educação. 2015. Disponível em http://www.cee.pa.gov.br/sites/default/files/PLANO \%20ESTADUAL $\% 20 D E \% 20 E D U C A \%$ C3\%87\%C3\%83O06052015 0.pdf. Acesso em 18 ago. 2017.

PARÁ. Relatório de Alunos com Deficiência por escola. Pará, 2017.

PARÁ. Secretaria de Educação do Pará, 2017.

PLETSCH, Márcia Denise. Deficiência Múltipla: formação de professores e processos de ensinoaprendizagem. Cadernos de Pesquisa, v. 45 n. 155, p. 12-29, jan./mar. 2015.

SENTANIN, Elisângela Ferreira. Formação continuada na modalidade a distância: análise do curso de especialização em gestão escolar, oferecido pela UFSCar em parceria com o MEC, 2017. 138 f. Tese (Doutorado), Faculdade de Ciências e Letras, Universidade Estadual Paulista, Araraquara. 
SILVA, Marta Henrique da; ABRANCHES, Sérgio Paulino. Formação Continuada de Professores no Contexto da Educação a Distância: concepções de docentes formadores sobre essa relação. Revista EaD \& Tecnologias Digitais na Educaşão, Dourados, MS, jan./nov., n. 4, v., 2015.

UEPA. Plano de Desenvolvimento Institucional. 2017.

Submetido em abril de 2020

Aprovado em novembro de 2020

\section{Informações da autora}

Ana Paula Cunha dos Santos Fernandes Universidade do Estado do Pará

E-mail: docenteapf@gmail.com

ORCID: https://orcid.org/0000-0003-1934-9221

Link Lattes: http://lattes.cnpq.br/8441289836978380 